Research Article

\title{
Influence of Microscopic Parameters on the Stress-Strain Relation in Rocks
}

\author{
Yanhui Cheng $\mathbb{D}^{1,2}$ and Weijun Yang ${ }^{1}$ \\ ${ }^{1}$ School of Civil Engineering, Changsha University of Science and Technology, Changsha 410114, China \\ ${ }^{2}$ School of Civil Engineering, Hunan University of City, Yiyang, Hunan 413000, China \\ Correspondence should be addressed to Yanhui Cheng; chengyanhuihn@126.com
}

Received 16 March 2018; Accepted 29 May 2018; Published 25 June 2018

Academic Editor: Rihong Cao

Copyright @ 2018 Yanhui Cheng and Weijun Yang. This is an open access article distributed under the Creative Commons Attribution License, which permits unrestricted use, distribution, and reproduction in any medium, provided the original work is properly cited.

Macromaterial properties should correspond to the mesoscopic parameters simulated in practical engineering problems. Discrete element contains a variety of particle models and its corresponding mesoscopic parameters, and the one-to-one relationship between the mesoscopic parameters and macroscopic parameters is difficult to establish. This paper studies the influence of microscopical characteristic parameters, such as particle contact stiffness ratio, parallel bond stiffness ratio, particle contact modulus, and parallel bond elastic modulus, on the stress-strain relation in rocks, which shows that (1) The range of particle contact stiffness ratio $k_{\mathrm{n}} / k_{\mathrm{s}}$ largely varies, but the stress-strain relation curve is relatively small. The particle contact stiffness has less influence on the elastic modulus of the simulated specimens than $k_{\mathrm{n}} / k_{\mathrm{s}}$. (2) Before the failure of the specimen, the axial strain corresponding to the peak compressive strength increases with the increase in the stiffness ratio $\overline{k_{\mathrm{n}}} / \overline{k_{\mathrm{s}}}$ of the parallel bond. (3) The particle contact modulus $E_{\mathrm{c}}$ has a great influence on the elastic modulus of sandstone and is characterized by the increase in the particle contact modulus $E_{\mathrm{c}}$, corresponding axial strain for the peak compressive strength decreases, and the slope of the stressstrain relationship curves before damage increases. (4) The elastic modulus of the parallel bond greatly influences the uniaxial compressive strength, and the relationship between them is proportional.

\section{Introduction}

Determination of the mechanical properties of rock is an important part of rock engineering design [1-4]. Rock mechanics parameters are usually obtained by laboratory tests and numerical analysis. Discrete element is a widely used numerical method in the study of rock micro- and macromechanical properties to solve the noncontinuous medium problem [5-8]. Scholars further used this technique to slope, mining, rock burst, debris flow, joint, and other practical projects where it obtained good simulation results [9-11]. First, macromaterial properties should correspond to the mesoscopic parameters simulated in practical engineering problems. However, discrete element contains a variety of particle models and its corresponding mesoscopic parameters, and the one-to-one relationship between the mesoscopic parameters and macroscopic parameters is difficult to establish [12-15]. Therefore, many scholars selected different particle bond models for macroscopic materials and studied the influence of microscopic parameters on macroproperties of materials [16-18]. For instance, the particles in PFC2D were used to contact the bond model by Huang and Detournay [19]. Yang et al. [16] adopted the parallel bond model and studied the effect of the microscopic parameters on Young's modulus, Poisson's ratio, and uniaxial compressive strength of the adhesive materials. The shear behavior of rock joints is numerically simulated using the discrete element code PFC2D by Bahaaddini et al. [17]. However, these studies mainly consider the parameters such as particle bonding strength, particle friction coefficient, and particle bond strength. Stiffness properties among mesoscopic particles affect the force between particles features affecting the macroscopic appearance of the material $[20,21]$. These properties include parallel bond stiffness ratio, particle contact modulus, and parallel to the compressive modulus of elasticity [22-24]. 
TABle 1: Mesoscopic parameters.

\begin{tabular}{lccc}
\hline Particle microscopic parameters & \multicolumn{3}{c}{ Parallel bonding microscopic parameters } \\
\hline Particle density $\left(\mathrm{kg} / \mathrm{m}^{3}\right)$ & 2205 & Parallel bond elastic modulus $(\mathrm{GPa})$ & 2.8 \\
Particle contact modulus $(\mathrm{GPa})$ & 2.8 & Normal strength $(\mathrm{MPa})$ & $20 \pm 4.5$ \\
Friction factor $\mu$ & 0.6 & Shear strength $(\mathrm{MPa})$ & $20 \pm 4.5$ \\
Particle contact stiffness ratio $k_{\mathrm{n}} / k_{\mathrm{s}}$ & 1.45 & Parallel bond stiffness ratio $k_{\mathrm{n}} / k_{\mathrm{s}}$ & 1.45 \\
\hline
\end{tabular}

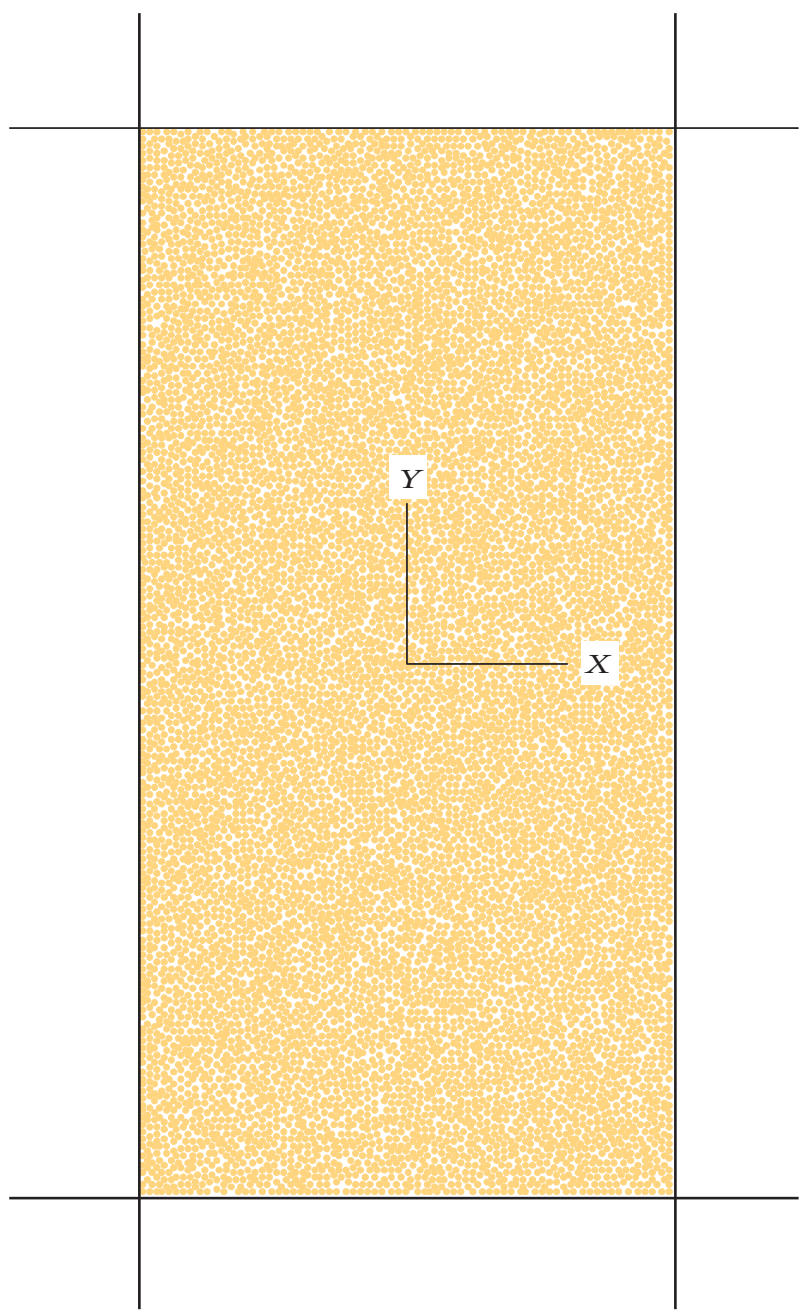

Figure 1: Granular aggregate.

Therefore, the influence of rigidity attribute of the particle on the macroscopic mechanical characteristics of the material must be further studied. Based on the considerations mentioned above, the use of the particle flow discrete element numerical simulation method (PFC), the condition of uniaxial compression, and material microstructures such as rock strength, stiffness parameters for the influence of the macroscopic mechanical behavior are studied in this paper.

\section{Modeling}

The mesoscopic parameters used in this paper are referred to the work by Bahaaddini et al. [5] and Cundall [25], as shown in Table 1. Figure 1 shows the numerical stimulation model with the height of $100 \mathrm{~mm}$ and diameter of $50 \mathrm{~mm}$. The
TABLE 2: Comparison of the simulation model and the results of the laboratory model.

\begin{tabular}{llccc}
\hline & & UCS $(\mathrm{MPa})$ & $E(\mathrm{GPa})$ & $v$ \\
\hline Laboratory results & Average value & 27.40 & 4.20 & 0.20 \\
Numerical results & Average value & 26.64 & 4.28 & 0.17
\end{tabular}

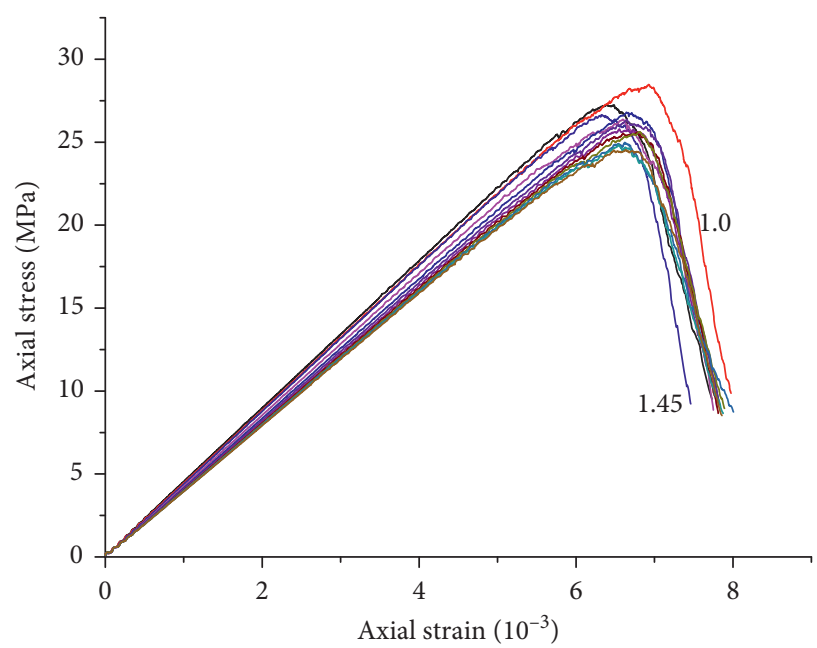

Particle contact stiffness ratio

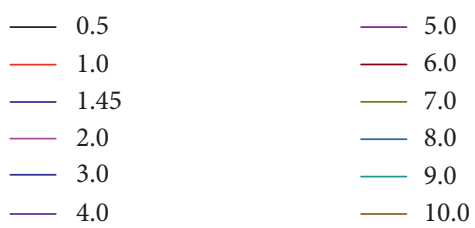

FIGURE 2: The stress-strain curves of different particle contact stiffness ratios are compared.

particle minimum diameter $D_{\min }=0.28 \mathrm{~mm}$, the maximum particle size of the particle is $D_{\max }=0.42 \mathrm{~mm}$, and the particle radius ratio is 1.5 , which is randomly generated between the maximum radius and the minimum radius. Also, the uniform distribution can be followed. Moreover, embedded Fish language by the servo control method is used to control the model of the "wall" movement to realize the uniaxial and conventional triaxial and the numerical simulation of the direct shear test $[26,27]$. A parallel bond model is used for particle bonding, and the parallel bonding radius is set to 1.0. The results of numerical simulation in this paper are compared with the indoor test results shown in Table 2 to verify the reliability of the model. In addition, the model used was $42 \mathrm{~mm}$ in diameter and $82 \mathrm{~mm}$ in height. Before calculating, the parameters should be verified [28-30]. Table 2 shows that the numerical simulation results of this paper are close to 
TABLE 3: The relationship between the particle contact stiffness ratio and macroscopic mechanical properties.

\begin{tabular}{lccc}
\hline Particle contact stiffness ratio & Modulus of elasticity $(\mathrm{GPa})$ & Poisson's ratio & Uniaxial compressive strength $(\mathrm{MPa})$ \\
\hline 0.5 & 4.39 & 0.136 & 27.26 \\
1 & 4.33 & 0.147 & 28.48 \\
1.45 & 4.22 & 0.157 & 27.06 \\
2 & 4.17 & 0.166 & 26.37 \\
3 & 4.06 & 0.178 & 26.80 \\
4 & 3.99 & 0.187 & 26.37 \\
5 & 3.94 & 0.193 & 25.80 \\
6 & 3.90 & 0.197 & 25.59 \\
7 & 3.87 & 0.201 & 25.63 \\
8 & 3.84 & 0.203 & 24.98 \\
9 & 3.82 & 0.205 & 24.84 \\
10 & 3.81 & 0.207 & 24.54 \\
\hline
\end{tabular}

those of the laboratory test results. It can be seen that the compressive strength of the numerical simulation is slightly less than that of the test results, and the elastic modulus is slightly larger than the test results, but the difference between them is very small.

\section{Influence of Microscopical Characteristic Parameters}

3.1. Particle Contact Stiffness Ratio. The particle contact stiffness ratio is the ratio of the contact stiffness of particles to the normal stiffness and tangential stiffness of $k_{\mathrm{n}} / k_{\mathrm{s}}$. The following steps should be performed to analyze the influence of $k_{\mathrm{n}} / k_{\mathrm{s}}$ on macroscopic mechanical behavior: change the parameter $k_{\mathrm{n}} / k_{\mathrm{s}}$, keep the other microscopic parameters unchanged, and obtain the stress-strain relation curve as shown in Figure 2. The relationship between the particle contact stiffness ratio $k_{\mathrm{n}} / k_{\mathrm{s}}$ and the macroscopic mechanical behavior of the simulated specimens was also investigated. Furthermore, the parameters of macroscopic mechanical properties under different particle contact stiffness ratio $k_{\mathrm{n}} / k_{\mathrm{s}}$ simulation tests can be obtained by the numerical simulation results of discrete element as shown in Table 3.

The elastic deformation stage occurs before specimen failure and is the stage where the stress-strain relationship is in a straight line. However, materials called elastomers cause the sudden destruction of the simulated specimen with the deformation properties of rock because the plastic deformation stage is not obvious. The range of particle contact stiffness ratio $k_{\mathrm{n}} / k_{\mathrm{s}}$ largely varies, but the stress-strain relation curve is relatively small. Uniaxial compressive strength change is small but can be seen when the particle contact stiffness $k_{\mathrm{n}} / k_{\mathrm{s}}$ is 1.0 . The particle contact stiffness $k_{\mathrm{n}} / k_{\mathrm{s}}$ for the axial strain can also be seen when the peak compressive strength and elastic limit range are small and when the uniaxial compressive strength reaches the maximum value. The slope of the stress-strain relation curve is relatively small, although the contact stiffness of the particles is larger than the range of variation. The particle contact stiffness has less influence on the elastic modulus of the simulated specimens than $k_{\mathrm{n}} / k_{\mathrm{s}}$. In general, the effect of particle contact stiffness on uniaxial compressive strength and elastic modulus $E$ in the macroscopic mechanical

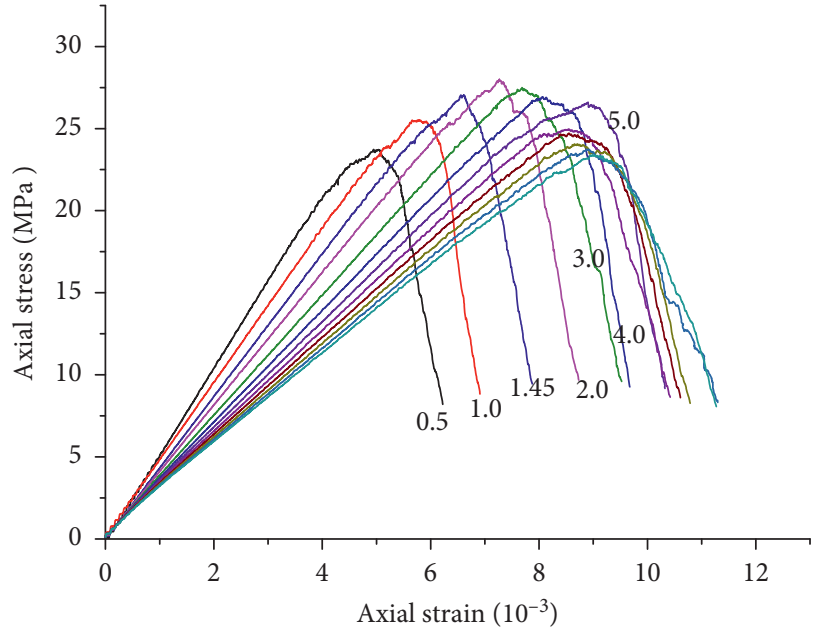

Parallel bonding stiffness ratio

$\begin{array}{ll}-0.5 & -5.0 \\ -1.0 & -6.0 \\ -1.45 & -7.0 \\ -2.0 & -8.0 \\ -3.0 & -9.0 \\ -4.0 & -10.0\end{array}$

FIGURE 3: Stress-strain relation for different parallel bonding stiffness ratios.

properties of the simulated specimens is small because the model used in this paper is a parallel bond model. Furthermore, the macroscopic mechanical properties of the specimens are mainly related to the microscopic parameters related to the parallel bonding.

3.2. Parallel Bond Stiffness Ratio. The parallel bonding stiffness ratio $\overline{k_{\mathrm{n}}} / \overline{k_{\mathrm{s}}}$ is a ratio of the normal stiffness $\overline{k_{\mathrm{n}}}$ to the shear stiffness $\overline{k_{\mathrm{s}}}$ of the two particles when the microscopic parameters are kept unchanged, and $\overline{k_{\mathrm{n}}} / \overline{k_{\mathrm{s}}}$ are the only ones changed. Numerical simulation of the uniaxial compression test is conducted to obtain the stress-strain relation curve of different parallel bond stiffness ratio $\overline{k_{\mathrm{n}}} / \overline{k_{\mathrm{s}}}$ situations as shown in Figure 3. The parameters of macroscopic mechanical properties are obtained based on the numerical simulation results of discrete elements as shown in Table 4. 
TABLE 4: Relation between the macromechanical properties with different parallel bonding stiffness ratios.

\begin{tabular}{lccc}
\hline Parallel bonding stiffness ratio & Elastic modulus $(\mathrm{GPa})$ & Poisson's ratio & Uniaxial compressive strength (MPa) \\
\hline 0.5 & 5.20 & 0.030 & 23.73 \\
1 & 4.70 & 0.107 & 25.51 \\
1.45 & 4.22 & 0.157 & 27.06 \\
2 & 3.90 & 0.190 & 28.00 \\
3 & 3.52 & 0.228 & 27.49 \\
4 & 3.26 & 0.251 & 26.92 \\
5 & 3.07 & 0.268 & 26.60 \\
6 & 2.93 & 0.280 & 24.97 \\
7 & 2.81 & 0.290 & 24.72 \\
8 & 2.72 & 0.297 & 24.06 \\
9 & 2.64 & 0.304 & 23.73 \\
10 & 2.57 & 0.310 & 23.38 \\
\hline
\end{tabular}

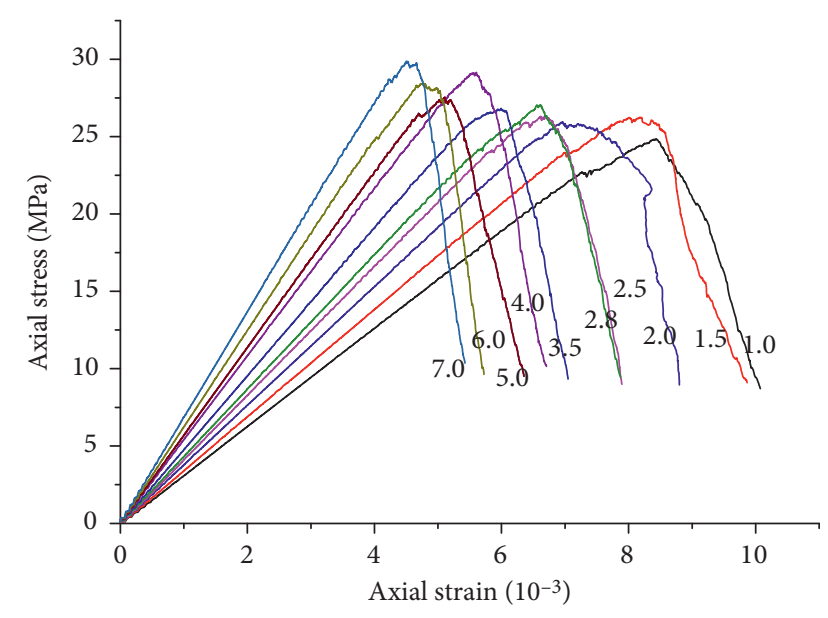

Particle contact modulus (GPa)

$\begin{array}{rr}-1.0 & -4.0 \\ -1.5 & -4.5 \\ -2.0 & -5.0 \\ 2.5 & -6.0 \\ 2.8 & -7.0 \\ -3.5 & \end{array}$

FIGURE 4: Stress-strain relation for different particle contact moduli.

Before the failure of the specimen, the axial strain corresponding to the peak compressive strength increases with the increase in the stiffness ratio $\overline{k_{\mathrm{n}}} / \overline{k_{\mathrm{s}}}$ of the parallel bond. The variation range of axial strain is nearly $4 \mathrm{~mm}$, and the elastic limit becomes smaller with the increase in the parallel bond stiffness ratio. The peak compressive strength reached a maximum of $28 \mathrm{MPa}$ at the time of parallel bond stiffness ratio 2.0. Conversely, when the parallel bond stiffness ratio is less than 2.0, the uniaxial compressive strength increases as the parallel bond stiffness ratio increases. When the increasing parallel bond stiffness ratio is greater than 2.0, the uniaxial compressive strength has slowly small increase. When the parallel bond stiffness ratio is greater than 5.0, the peak compressive strength decreases significantly. This phenomenon is caused by the gradual increase in the parallel bond stiffness ratio. In addition, the parallel bond's normal stiffness is greater than the tangential stiffness; specimen "rigid" enhanced by plastic deformation damage to brittle failure mode change gradually become a rigid body, and the uniaxial compressive strength decreases. The slope of the stress-strain relation curve before the sudden failure also decreases with the increase in the parallel bond stiffness ratio. The effect of the parallel bond stiffness on the elastic modulus of the specimens is relatively large and inversely proportional to each other. This phenomenon is caused by the high rigidity of the parallel bond between particles. A strong "rigidity" indicates small "elasticity" and small macroscopic elastic modulus.

3.3. Particle Contact Modulus. The particle contact modulus $E_{\mathrm{c}}$ is the elastic modulus of contact between particles. Certain deformation occurs when the pellet is affected by the force. Figure 4 shows the stress-strain of the obtained relation of particle contact modulus $E_{\mathrm{c}}$. The relationship between the particle contact modulus $E_{\mathrm{c}}$ and the macroscopic mechanical behavior of the simulated specimens is also discussed. In addition, Table 5 shows the parameters of macroscopic mechanical properties under different particle contact modulus $E_{\mathrm{c}}$ simulation tests obtained by the numerical simulation results of discrete elements.

Figure 4 shows that the particle contact modulus $E_{\mathrm{c}}$ has a great influence on the stress-strain relation curve. The particle contact modulus $E_{\mathrm{c}}$ has a great influence on the elastic modulus of sandstone and is characterized by the increase in the particle contact modulus $E_{\mathrm{c}}$, corresponding axial strain for the peak compressive strength decreases, and the slope of the stress-strain relationship curves before damage increases. This phenomenon is also caused by the increase in the particle contact modulus $E_{\mathrm{c}}$ which increases the elastic modulus $E$ of macroscopic materials. The uniaxial compressive strength has the general increasing trend with the increasing particle contact modulus $E_{\mathrm{c}}$, but the amplitude of increase is relatively small. Hence, the particle contact modulus $E_{\mathrm{c}}$ minimally affects the uniaxial compressive strength, and the variation is not evident.

3.4. Parallel Bond Elastic Modulus. The elastic modulus of the parallel bond $\overline{E_{c}}$ is the elastic modulus of the material 
TABLE 5: Relation between the macromechanical properties with different particle contact moduli.

\begin{tabular}{|c|c|c|c|}
\hline Particle contact modulus GPa) & Elastic modulus (GPa) & Poisson's ratio & Uniaxial compressive strength $(\mathrm{MPa})$ \\
\hline 1 & 3.09 & 0.121 & 24.85 \\
\hline 1.5 & 3.40 & 0.130 & 26.25 \\
\hline 2 & 3.73 & 0.141 & 25.95 \\
\hline 2.5 & 4.06 & 0.149 & 26.32 \\
\hline 2.8 & 4.22 & 0.157 & 27.06 \\
\hline 3.5 & 4.64 & 0.170 & 26.81 \\
\hline 4 & 4.89 & 0.180 & 27.54 \\
\hline 4.5 & 5.24 & 0.187 & 29.15 \\
\hline 5 & 5.49 & 0.194 & 27.53 \\
\hline 6 & 6.00 & 0.207 & 28.44 \\
\hline 7 & 6.52 & 0.224 & 29.86 \\
\hline
\end{tabular}

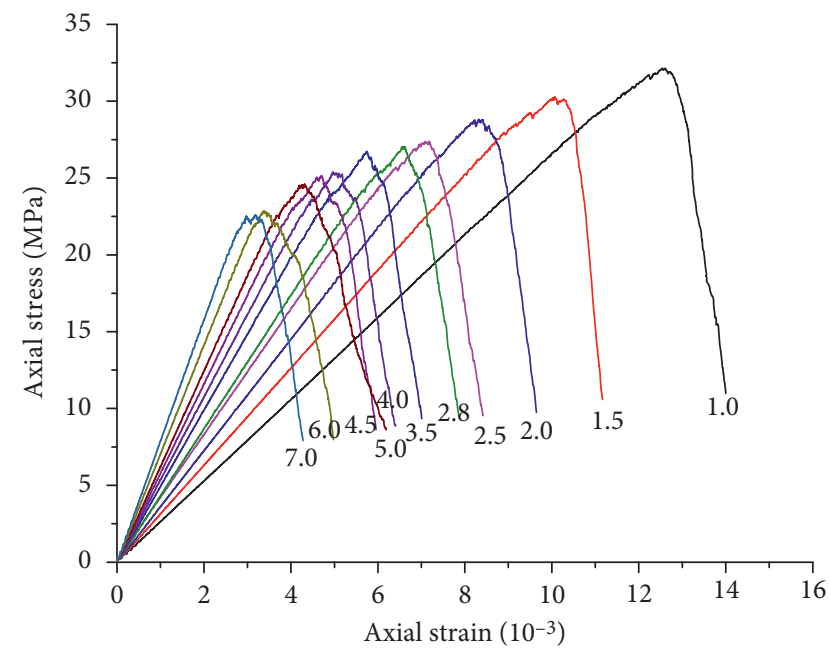

Elastic modulus of the parallel bond (GPa)

$\begin{array}{rr}1.0 & -4.0 \\ -1.5 & -4.5 \\ 2.0 & -5.0 \\ -2.5 & -6.0 \\ -2.8 & 7.0 \\ - & 3.5\end{array}$

FIGURE 5: Stress-strain relation for different elastic moduli of the parallel bond.

between two particles in each parallel bond model. Figure 5 shows the stress-strain relation curve. Table 6 shows the parameters of macroscopic mechanical properties obtained from the numerical simulation results of discrete elements.

Figure 5 also shows that the parallel bonded elastic modulus greatly influences the stress-strain curve most notably with the parallel bond and when the increase in the elastic modulus and uniaxial compressive strength is large. The elastic modulus of the parallel bond greatly influences the uniaxial compressive strength, and the relationship between them is proportional. Before the failure of the test piece, the axial strain and elastic limit corresponding to the peak compressive strength decrease with the increase in the elastic modulus of the parallel bond. This phenomenon is caused by the increase in the slope of the stress-strain relation curve, which increases the elastic modulus of the
TABLE 6: Relation between the macromechanical properties with different elastic moduli of the parallel bond.

\begin{tabular}{lccc}
\hline $\begin{array}{l}\text { Elastic modulus of } \\
\text { the parallel bond } \\
(\mathrm{GPa})\end{array}$ & $\begin{array}{c}\text { Elastic } \\
\text { modulus } \\
(\mathrm{GPa})\end{array}$ & $\begin{array}{c}\text { Poisson's } \\
\text { ratio }\end{array}$ & $\begin{array}{c}\text { Uniaxial } \\
\text { compressive } \\
\text { strength }(\mathrm{MPa})\end{array}$ \\
\hline 1 & 2.49 & 0.238 & 32.14 \\
1.5 & 3.02 & 0.200 & 30.28 \\
2 & 3.50 & 0.178 & 28.82 \\
2.5 & 4.02 & 0.158 & 27.39 \\
2.8 & 4.22 & 0.157 & 27.06 \\
3.5 & 4.83 & 0.146 & 26.73 \\
4 & 5.25 & 0.140 & 25.37 \\
4.5 & 5.67 & 0.135 & 25.12 \\
5 & 6.09 & 0.132 & 24.61 \\
6 & 6.92 & 0.126 & 22.85 \\
7 & 7.74 & 0.123 & 22.59 \\
\hline
\end{tabular}

parallel bond. Therefore, the elastic modulus of the parallel bond that greatly influences the elastic modulus $E$ of the simulated specimens mainly affects the elastic modulus of the parallel bond.

\section{Conclusions}

(1) The range of the particle contact stiffness ratio $k_{\mathrm{n}} / k_{\mathrm{s}}$ largely varies, but the stress-strain relation curve is relatively small. Uniaxial compressive strength change is small. The slope of the stress-strain relation curve is relatively small, although the contact stiffness of the particles is larger than the range of variation. The particle contact stiffness has less influence on the elastic modulus of the simulated specimens than $k_{\mathrm{n}} / k_{\mathrm{s}}$.

(2) Before the failure of the specimen, the axial strain corresponding to the peak compressive strength increases with the increase in the stiffness ratio $\overline{k_{\mathrm{n}}} / \overline{k_{\mathrm{s}}}$ of the parallel bond. Conversely, when the parallel bond stiffness ratio is less than 2.0, the uniaxial compressive strength increases as the parallel bond stiffness ratio increases. When the increasing parallel bond stiffness ratio is greater than 2.0, the uniaxial compressive strength has slowly small increase. When the parallel bond stiffness ratio is greater than 5.0, the peak compressive strength decreases significantly. The slope of the stress-strain relation 
curve before the sudden failure also decreases with the increase in the parallel bond stiffness ratio.

(3) The particle contact modulus $E_{c}$ has a great influence on the elastic modulus of sandstone and is characterized by the increase in particle contact modulus $E_{\mathrm{c}}$, corresponding axial strain for the peak compressive strength decreases, and the slope of the stress-strain relationship curves before damage increases. The uniaxial compressive strength has the general increasing trend with the increasing particle contact modulus $E_{\mathcal{c}}$, but the amplitude of increase is relatively small.

(4) The elastic modulus of the parallel bond greatly influences the uniaxial compressive strength, and the relationship between them is proportional. Before the failure of the test piece, the axial strain and elastic limit corresponding to the peak compressive strength decreases with the increase in the elastic modulus of the parallel bond.

\section{Data Availability}

The data used to support the findings of this study are available from the corresponding author upon request.

\section{Conflicts of Interest}

The authors declare no conflicts of interest.

\section{References}

[1] S. H. Chong, J. W. Kim, and G. C. Cho, "Rock mass dynamic test apparatus for estimating the strain-dependent dynamic properties of jointed rock masses," Geotechnical Testing Journal, vol. 37, no. 2, pp. 311-318, 2014.

[2] Y. J. Hou, D. L. Zhang, and F. L. Guo, "Influences of support on mechanical property of rock in water-containing tunnel," Journal of Central South University, vol. 41, no. 3, pp. 11521157, 2010.

[3] W. Liang, C. Yang, Y. Zhao, M. B. Dusseault, and J. Liu, "Experimental investigation of mechanical properties of bedded salt rock," International Journal of Rock Mechanics and Mining Sciences, vol. 44, no. 3, pp. 400-411, 2007.

[4] Q. Z. Zhang, H. S. Jang, D. S. Bae, G. Y. Kim, and B. A. Jang, "Empirical rock mechanical site-descriptive modeling (RMSDM) for the Korea Atomic Energy Research Institute Underground Research Tunnel (KURT)," Environmental Earth Sciences, vol. 75, no. 10, p. 860, 2016.

[5] M. Bahaaddini, G. Sharrock, and B. K. Hebblewhite, "Numerical investigation of the effect of joint geometrical parameters on the mechanical properties of a non-persistent jointed rock mass under uniaxial compression," Computers and Geotechnics, vol. 49, no. 20, pp. 206-225, 2013.

[6] X. Ding, L. Zhang, H. Zhu, and Q. Zhang, "Effect of model scale and particle size distribution on PFC3D simulation results," Rock Mechanics and Rock Engineering, vol. 47, no. 6, pp. 2139-2156, 2014.

[7] R.-h. Cao and H. Lin, "Experimental and numerical study of failure behavior and energy mechanics of rock-like materials containing multiple joints," Advances in Materials Science and Engineering, vol. 2017, Article ID 6460150, 17 pages, 2017.
[8] X. Fan, P. H. S. W. Kulatilake, X. Chen, and P. Cao, "Crack initiation stress and strain of jointed rock containing multicracks under uniaxial compressive loading: a particle flow code approach," Journal of Central South University, vol. 22, no. 2, pp. 638-645, 2015.

[9] J. W. Park and J. J. Song, "Numerical simulation of a direct shear test on a rock joint using a bonded-particle model," International Journal of Rock Mechanics and Mining Sciences, vol. 46, no. 8, pp. 1315-1328, 2009.

[10] T. J. Cui, M. A. Yun-Dong, and L. G. Wang, "Blasting process simulation and stability study of an open mine slope based on PFC3D," Applied Mathematics and Mechanics, vol. 35, no. 7, pp. 759-767, 2014.

[11] D. D. Tannant and C. Wang, "Thin tunnel liners modelled with particle flow code," Engineering Computations, vol. 21, no. 2, pp. 318-342, 2013.

[12] B. K. Mishra, "A review of computer simulation of tumbling mills by the discrete element method: part II-practical applications," International Journal of Mineral Processing, vol. 71, no. 1, pp. 73-93, 2003.

[13] H. Kruggel-Emden, E. Simsek, S. Rickelt, S. Wirtz, and V. Scherer, "Review and extension of normal force models for the discrete element method," Powder Technology, vol. 171, no. 3, pp. 157-173, 2007.

[14] D. He and Y. Cheng, "Numerical simulation for mechanical behavior of asphalt pavement with graded aggregate base," Advances in Civil Engineering, vol. 2018, Article ID 1404731, 9 pages, 2018.

[15] H. Lin, W. Xiong, and Q. Yan, "Three-dimensional effect of tensile strength in the standard Brazilian test considering contact length," Geotechnical Testing Journal, vol. 39, no. 1, pp. 137-143, 2016.

[16] B. Yang, Y. Jiao, and S. Lei, "A study on the effects of microparameters on macroproperties for specimens created by bonded particles," Engineering Computations, vol. 23, no. 6, pp. 607-631, 2006.

[17] M. Bahaaddini, G. Sharrock, and B. K. Hebblewhite, "Numerical direct shear tests to model the shear behaviour of rock joints," Computers and Geotechnics, vol. 51, no. 51, pp. 101-115, 2013.

[18] R. Cao, P. Cao, H. Lin, and X. Fan, "Experimental and numerical study of the failure process and energy mechanisms of rock-like materials containing cross un-persistent joints under uniaxial compression," PLoS One, vol. 12, no. 12, Article ID e0188646, 2017.

[19] H. Huang and E. Detournay, "Discrete element modeling of tool-rock interaction II: rock indentation," International Journal for Numerical and Analytical Methods in Geomechanics, vol. 37, no. 13, pp. 1913-1929, 2013.

[20] J. Hadjigeorgiou, K. Esmaieli, and M. Grenon, "Stability analysis of vertical excavations in hard rock by integrating a fracture system into a PFC model," Tunnelling and Underground Space Technology, vol. 24, no. 3, pp. 296-308, 2009.

[21] Z. Liu, N. Zhou, and J. Zhang, "Random gravel model and particle flow based numerical biaxial test of solid backfill materials," International Journal of Mining Science and Technology, vol. 23, no. 4, pp. 463-467, 2013.

[22] S. Utili and R. Nova, "DEM analysis of bonded granular geomaterials," International Journal for Numerical and Analytical Methods in Geomechanics, vol. 32, no. 17, pp. 19972031, 2008.

[23] G. Yan, H. S. Yu, and G. Mcdowell, "Simulation of granular material behaviour using DEM," Procedia Earth and Planetary Science, vol. 1, no. 1, pp. 598-605, 2009. 
[24] J. Liu, P. Cao, and D. Han, "The influence of confining stress on optimum spacing of TBM cutters for cutting granite," International Journal of Rock Mechanics and Mining Sciences, vol. 88, pp. 165-174, 2016.

[25] P. Cundall, "A computer model for simulating progressive large scale movement in block rock systems," in Proceedings of the International Symposium on Rock Mechanics, pp. 11-18, Nancy, France, October 1971.

[26] J. Yoon, "Application of experimental design and optimization to PFC model calibration in uniaxial compression simulation," International Journal of Rock Mechanics and Mining Sciences, vol. 44, no. 6, pp. 871-889, 2007.

[27] A. S. Tawadrous, D. Degagné, M. Pierce, and D. Mas Ivars, "Prediction of uniaxial compression PFC3D model microproperties using artificial neural networks," International Journal for Numerical and Analytical Methods in Geomechanics, vol. 33, no. 18, pp. 1953-1962, 2009.

[28] S. D. A. Kumari and T. G. Sitharam, "Effect of aspect ratio on the monotonic shear behaviour: micromechanical interpretations," Geotechnical and Geological Engineering, vol. 31, no. 5, pp. 1543-1553, 2013.

[29] X. Wang, Z. J. Wen, and Y. J. Jiang, "Time-space effect of stress field and damage evolution law of compressed coalrock," Geotechnical and Geological Engineering, vol. 34, no. 6, pp. 1-8, 2016.

[30] D. Wijewickreme, A. Dabeet, and P. Byrne, "Some observations on the state of stress in the direct simple shear test using 3D discrete element analysis," Geotechnical Testing Journal, vol. 36, no. 2, pp. 292-299, 2013. 


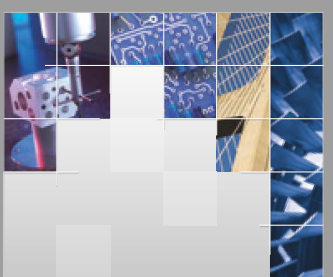

\section{Enfincering}
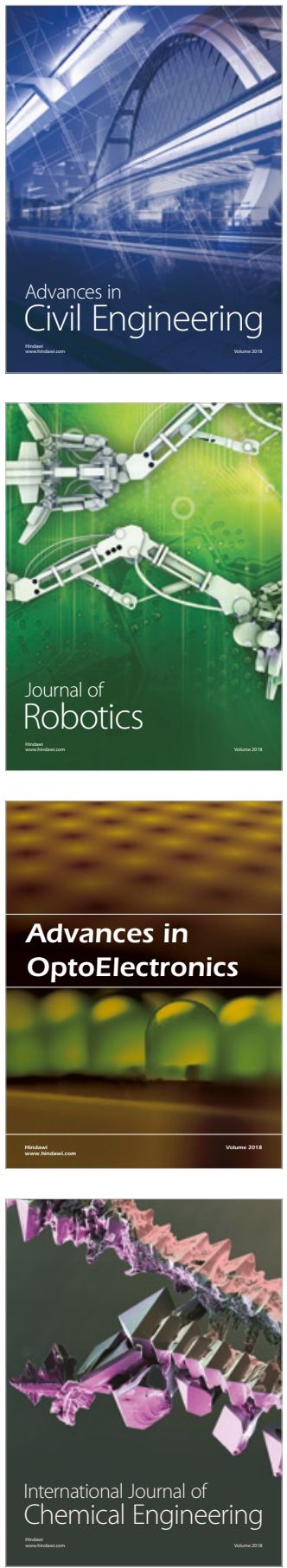

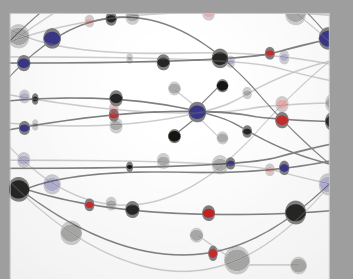

\section{Rotating \\ Machinery}

The Scientific World Journal

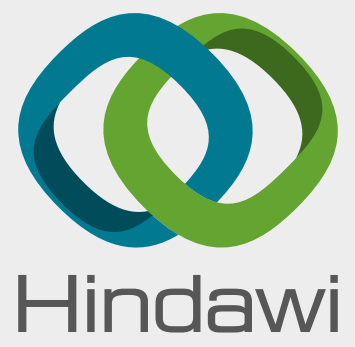

Submit your manuscripts at

www.hindawi.com
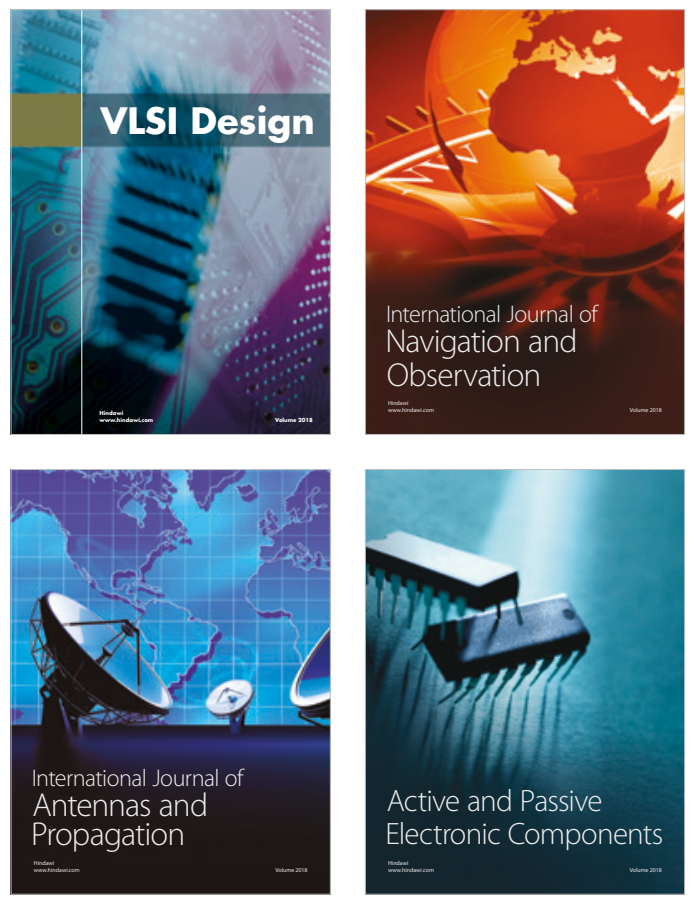
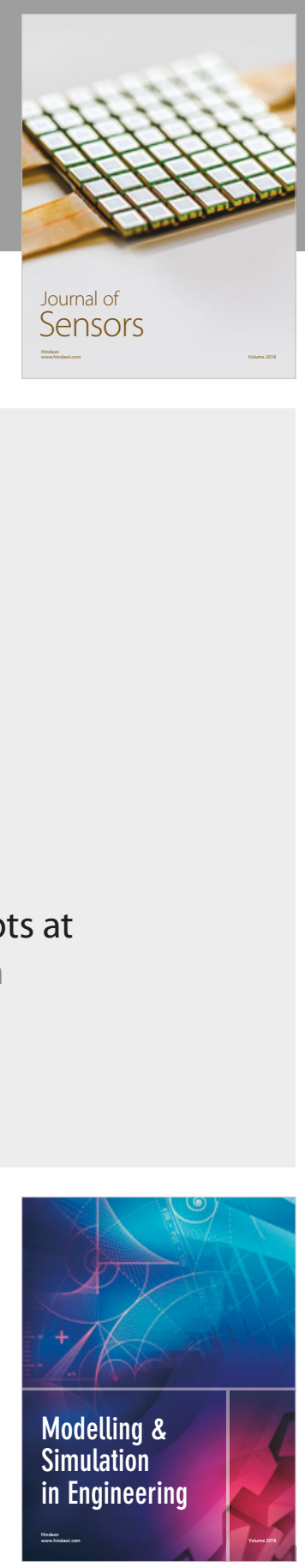

\section{Advances \\ Multimedia}
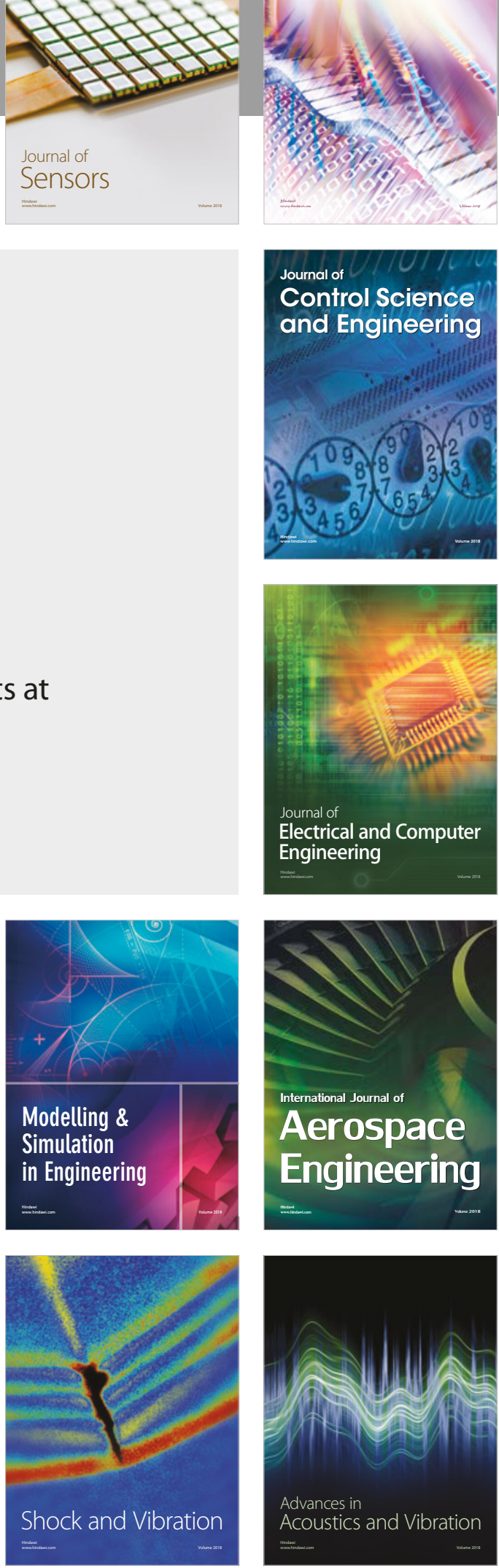